\title{
Implantes
}

\section{Evolução temporal da interfase aço inoxidável P558/solução de cloreto de sódio por espectroscopia de impedância eletroquímica}

Ruth Flavia Vera Villamil Jaimes

Villares Metals S.A., Instituto de Química da Universidade de São Paulo- Faculdade de Ciências da Fundação InstitutoTecnológico de Osasco - E-mail: rfvillam@iq.usp.br

Mónica Luisa Chaves de Andrade Afonso Instituto de Química da Universidade de São Paulo.E-mail: monica@iq.usp.br

Silvia Maria Leite Agostinho Instituto de Química da Universidade de São Paulo. E-mail: smlagost@iq.usp.br

Celso Antonio Barbosa

Villares Metals S.A. E-mail: celso.barbosa@villaresmetals.com.br

\section{Resumo}

O aço inoxidável P558, isento de níquel, vem sendo estudado pelo grupo com o objetivo de verificar a viabilidade do seu emprego em implantes ortopédicos. Em trabalhos anteriores, foi mostrado, por técnicas eletroquímicas estacionárias, que ele apresenta, em meio de cloreto de sódio 0,11 mol L-1, comportamento semelhante ao do aço ISO 5832-9 e bem superior ao do aço ISO 5832-1, mais conhecido como F138. Nesse trabalho, foi estudada a evolução temporal da interfase aço inoxidável P558/ $\mathrm{NaCl}$ $0,11 \mathrm{~mol} \mathrm{~L}^{-1}$ empregando a técnica de espectroscopia de impedância eletroquímica, no potencial de circuito aberto. Os intervalos de tempo observados foram de $10 \mathrm{~min}, 1$ dia, 2 dias e 5 dias. Observou-se que o filme passivo se torna mais protetor, com o decorrer do tempo. Foi feita simulação dos resultados experimentais através de circuitos elétricos equivalentes, que permitiram sugerir a existência, no início da observação, de apenas um filme passivante menos protetor e, quando atingida a condição estacionária, a existência de um segundo filme mais compacto.

Palavras-chave: Aço inoxidável P558, espectroscopia de impedância eletroquímica, circuitos equivalentes.

\begin{abstract}
P558 stainless steel, nickel free, has been studied by this group with the purpose of verifying its viability for use in orthopedic implants. In previous works, it has been shown by stationary electrochemical techniques that this steel presents a similar behavior of that presented by ISO 5832-9 with a corrosion resistance significantly higher when compared to ISO 5832-1 stainless steel, usually known as F138 SS. In this work the temporal evolution of the interfase P558/ $\mathrm{NaCl}$ $0.11 \mathrm{~mol} \mathrm{~L}^{-1}$ was studied by electrochemical impedance spectroscopy, at the open circuit potential. The time intervals observed were $10 \mathrm{~min}$. 1 day, 2 days and 5 days. It was observed that the passive film became more protective with the increase of time. The experimental data was modeled using the equivalent electrical circuit approach. This approach suggested an initial existence of a slightly protective passive film, which then permitted the formation of a more compact secondary film upon stabilization of the conditions.
\end{abstract}

Keywords: P558 stainless steel, electrochemical impedance spectroscopy, equivalent circuits. 


\section{Introdução}

A procura de novos materiais metálicos, aplicados em implantes ortopédicos, tais como os aços inoxidáveis austeníticos, tem se intensificado nesses últimos anos. No entanto, grande tem sido a preocupação em desenvolver aços inoxidáveis especiais isentos de níquel, em virtude de esse elemento ser o responsável por processos alérgicos em um número significativo de pacientes [1,2]. Por essa razão, aços inoxidáveis contendo teores relativamente elevados de manganês e nitrogênio em lugar de níquel, preservando a estrutura austenítica, vêm sendo estudados [1-6].

Villamil et al. [7-10] têm avaliado o comportamento eletroquímico do aço ISO 5832-9 (ASTM F 1586-95), empregando curvas de polarização potenciostática e potenciodinâmica à baixa velocidade de varredura, cronoamperometria e impedância eletroquímica. Foi mostrado que o referido aço, em meios que simulam fluidos biológicos, se mostra passivado até o potencial de transpassivação, ao contrário dos aços ISO 5832-1 (ASTM F13892) e 316 L (ASTM 276-00), que apresentam, nos mesmos meios, potencial de pite.

O aço inoxidável P558, isento de níquel, vem sendo estudado pelo grupo com o objetivo de verificar a viabilidade do seu emprego em implantes ortopédicos. Em trabalhos anteriores [13-16], foi mostrado, por técnicas eletroquímicas estacionárias, que este aço apresenta, em meio de cloreto de sódio $0,11 \mathrm{~mol} \mathrm{~L}^{-1}$, comportamento semelhante ao do aço ISO 5832-9 e, significativamente, superior ao do aço ISO 5832-1, mais conhecido como F138. Através de curvas de polarização potenciodinâmica a $1 \mathrm{mV} / \mathrm{s}$, foi mostrado que o aço P558 se encontra passivado desde o potencial de circuito aberto estacionário até o potencial de transpassivação (1050 mV/ECS). Ensai- os da superfície por microscopica eletrônica de varredura após a polarização anódica confirmaram a ausência de corrosão localizada no aço P558.

Nesse trabalho, foi estudada a evolução temporal da interfase aço inoxidável P558/NaCl 0,11 mol L-1 , empregando a técnica de espectroscopia de impedância eletroquímica, no potencial de circuito aberto, com o objetivo de determinar o intervalo de tempo necessário para se obter a condição estacionária na interfase.

\section{Materiais e métodos Substrato metálico}

Aço inoxidável P 558. A Tabela 1 apresenta a composição química em porcentagem em massa do aço P 558.

\section{Solução}

A solução empregada foi de $\mathrm{NaCl}$ $0,15 \mathrm{~mol} \mathrm{~L}^{-1}$ à temperatura de $37^{\circ} \mathrm{C}$.

\section{Equipamentos}

Foi empregado um potenciostato $\mu$ Autolab tipo III/FRA2 acoplado a um microcomputador e ao analisador de impedância.

Os eletrodos de trabalho consistiram de discos do aço inoxidável P558 com área exposta à solução de 0,32 cm², os quais foram previamente lixados com lixa comum de carbeto de silício (SiC), de granulometrias 300, 400 e 600, lavados com água destilada e álcool etílico e secos em jato de ar quente.

Os ensaios eletroquímicos foram realizados utilizando um esquema clássico de três eletrodos, com um eletrodo de calomelano saturado (ECS) e um ele- trodo de platina (com grande área), funcionando como referência e contra-eletrodo, respectivamente.

\section{Metodologia}

Os diagramas de impedância foram obtidos no intervalo de freqüência entre 100 kHz e 3 mHz, a uma taxa de aquisição de 5 pontos por década e com amplitude de perturbação de $8 \mathrm{mV}$. Todos os ensaios foram realizados no potencial de circuito aberto a intervalos de tempo iguais a $10 \mathrm{~min}, 24 \mathrm{~h}, 48 \mathrm{~h}$ e $120 \mathrm{~h}$. Todas as curvas foram levantadas pelo menos três vezes. As medidas foram realizadas com eletrodo parado.

\section{Resultados e discussão}

A Figura 1a (diagrama de Nyquist) mostra que o filme passivo se torna mais protetor, com o decorrer do tempo: o diagrama de Nyquist correspondente a 10 minutos de imersão (Figuras 1a ampliada) apresenta tendência de fechamento de arco, com grande diminuição nos valores, tanto da parte real, como da parte imaginária da impedância, quando comparada com os diagramas de Nyquist registrados a maiores tempos de imersão. Após 1 dia de imersão, observa-se um comportamento típico de superfície passivada em toda a faixa de freqüência investigada, caracterizado por elevados valores de impedância, no potencial de circuito aberto. Entretanto uma observação mais detalhada dos diagramas de Bode representados nas Figuras 1b permite verificar a presença de, pelo menos, duas constantes de tempo nítidas para freqüências intermediárias e baixas (dois máximos no diagrama de ângulo de fase de Bode). Verifica-se que a segunda constante de tempo, observada nas freqüências mais baixas, apresenta um au-

Tabela 1 - Composição química, em \% em massa, do aço P 558.

\begin{tabular}{c|c|c|c|c|c|c|c|c|c|c}
\hline Grade & $\mathbf{C}$ & $\mathbf{S i}$ & $\mathbf{M n}$ & $\mathbf{C r}$ & $\mathbf{N i}$ & $\mathbf{M o}$ & $\mathbf{N b}$ & $\mathbf{N}$ & $\mathbf{P}$ & $\mathbf{S}$ \\
\hline P 558 & 0,18 & 0,4 & 9,9 & 16,7 & 0,014 & 3,3 & - & 0,48 & - & - \\
\hline
\end{tabular}


Ruth Flavia Vera Villamil Jaimes et al.

mento considerável do ângulo de fase, com o tempo de imersão.

Analisando, conjuntamente, os diagramas de Nyquist e de Bode, verificase que o processo que ocorre a freqüências mais baixas é o responsável pela maior resistência à corrosão. Pode sugerirse a formação de um segundo filme de características mais protetoras, mostrando-se mais estável após dois dias de imersão. A presença de duas constantes de tempo também foi observada por Rondeli [1] para esse mesmo aço em meio fisiológico contendo proteína.

Com o intuito de melhor entender a interfase estudada, foi feita a simulação dos dados experimentais por circuitos equivalentes. Os circuitos que melhor se adaptaram aos resultados (Figura 2) indicam a presença de um segundo filme já no tempo de imersão de 10 minutos (Figura 3). As resistências $R_{1}$ e $R_{2}$ (Tabela 2) obtidas a 10 minutos, entretanto, são, significativamente, mais baixas quando comparadas com as resistências a tempos de imersão maiores. O elemento de fase constante $C P E_{1}$ correspondente a 10 minutos apresenta um valor elevado, sugerindo a presença de espécies carregadas na superfície do eletrodo e o valor do declive do elemento de fase constante $n$ do $\mathrm{CPE}_{2}$ indica a presença de processos difusivos $(n=0,66)$. Esses parâmetros sugerem um filme em estágio de formação. Para tempos de imersão maio-

res, da ordem de 24h (Figura 4), as resistências $\mathrm{R}_{1}$ e $\mathrm{R}_{2}$ (Tabela 2) aumentam, significativamente, de duas ordens de grandeza, atingindo valores mais elevados nos tempos de 48h e 120h; e o valor de $n$ do $C P E_{2}$ indica fenômenos majoritariamente capacitivos, sugerindo que o segundo filme já se formou. É interessante notar que os resultados obtidos após 48h (Figura 5) e 120h (Figura 6) de imersão são comparáveis. O alargamento do máximo do ângulo de fase a baixas freqüências para $120 \mathrm{~h}$ pode ser atribuído à presença de mais de um processo faradaico, com constantes de tempo próximas, na formação do filme protetor, justificando o elemento de fase constante $\mathrm{CPE}_{3}$ e a resistência $\mathrm{R}_{3}$.

\section{Conclusões}

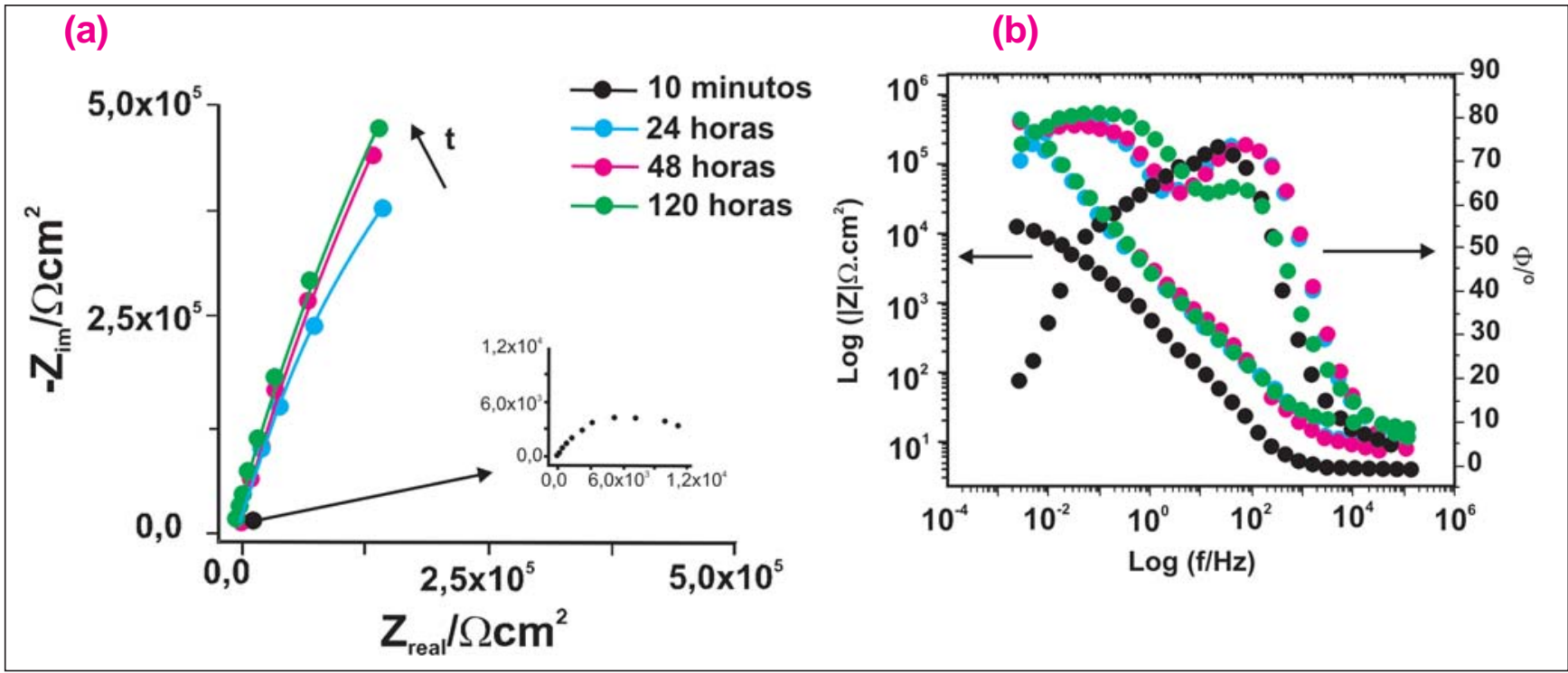

Figura 1 - Diagramas de impedância na forma (a) Nyquist e (b), Bode, correspondentes a tempos diferentes de imersão do aço P558 em meio de $\mathrm{NaCl} 0,11 \mathrm{~mol} \mathrm{~L}^{-1}$. $\mathrm{E}=$ potencial de circuito aberto.

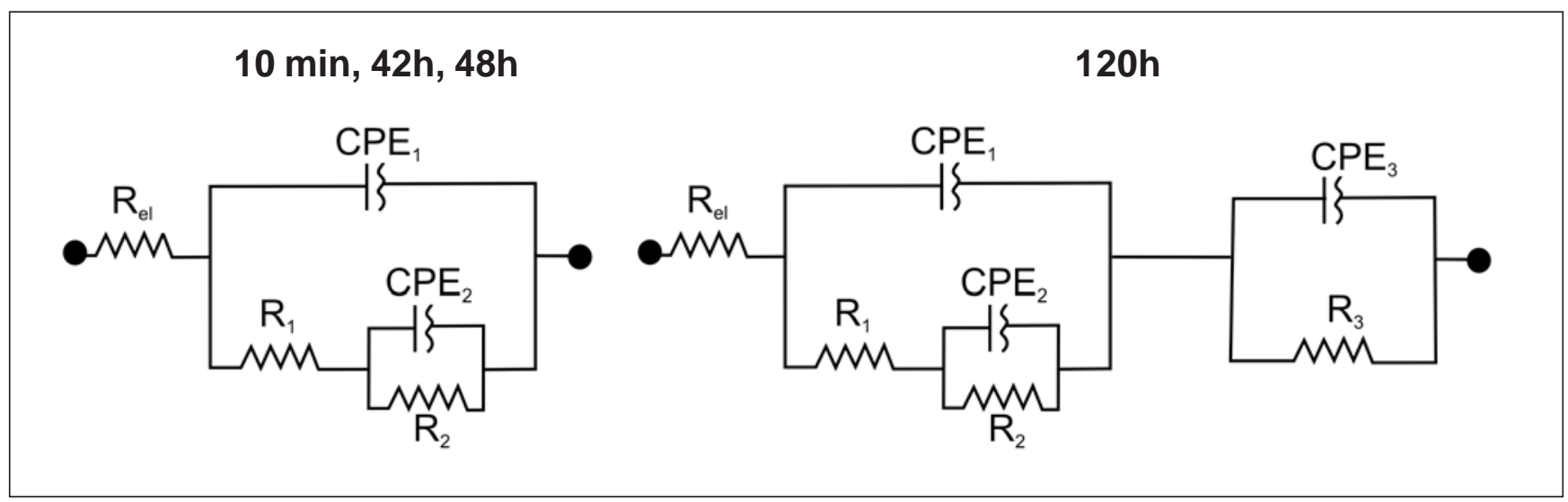

Figura 2 - Circuitos equivalentes utilizados na simulação dos dados experimentais do aço P558 imerso em NaCl 0,11 mol L-1 com diferentes tempos de imersão. 
Evolução temporal da interfase aço inoxidável P558/solução de cloreto de sódio por espectroscopia...

Tabela 2 - Parâmetros do ajuste não linear obtidos para os vários sistemas. $\chi^{2}<10^{-4}$.

\begin{tabular}{|c|c|c|c|c|c|c|c|c|c|c|}
\hline \multicolumn{5}{|c|}{$\mathrm{CPE}_{1}$} & \multicolumn{3}{|c|}{$\mathrm{CPE}_{2}$} & \multicolumn{3}{|c|}{$\mathrm{CPE}_{3}$} \\
\hline $\begin{array}{c}\mathrm{E} \\
\mathrm{ImV}\end{array}$ & $\begin{array}{c}\mathbf{R}_{\mathrm{el}} \\
/ \Omega \mathrm{cm}^{2}\end{array}$ & $\begin{array}{c}\mathrm{R}_{1} \\
/ \mathrm{k} \Omega \mathrm{cm}^{2}\end{array}$ & $\begin{array}{c}\mathrm{y}_{0} \\
/ \mu \mathrm{Fcm}^{-2}\end{array}$ & $\mathrm{n}$ & $\begin{array}{c}\mathrm{R}_{2} \\
/ \mathrm{k} \Omega \mathrm{cm}^{2}\end{array}$ & $\begin{array}{c}\mathrm{y}_{0} \\
/ \mu \mathrm{Fcm}^{-2}\end{array}$ & $\mathbf{n}$ & $\begin{array}{c}\mathbf{R}_{3} \\
/ \Omega \mathrm{cm}^{2}\end{array}$ & $\begin{array}{c}y_{0} \\
I \Omega^{-1} \mathrm{~s}^{-n} \mathrm{~cm}^{-2}\end{array}$ & $\mathrm{n}$ \\
\hline $10 \mathrm{~min}$. & 4 & 14 & 228 & 0,88 & 0,6 & $\begin{array}{c}3 \times 10^{-3} \\
/ \Omega^{-1} \cdot \mathrm{s}^{-n} \cdot \mathrm{cm}^{-2}\end{array}$ & 0,66 & - & - & - \\
\hline $24 \mathrm{H}$ & 10 & 2240 & 34 & 0,88 & 3 & 41 & 0,88 & - & - & - \\
\hline $48 \mathrm{H}$ & 9 & 4032 & 34 & 0,88 & 2 & 38 & 0,89 & -- & - & -- \\
\hline $120 \mathrm{H}$ & 16 & 3584 & 38 & 0,88 & 1 & 31 & 0,91 & 10 & $4 \times 10^{-4}$ & 0,58 \\
\hline
\end{tabular}

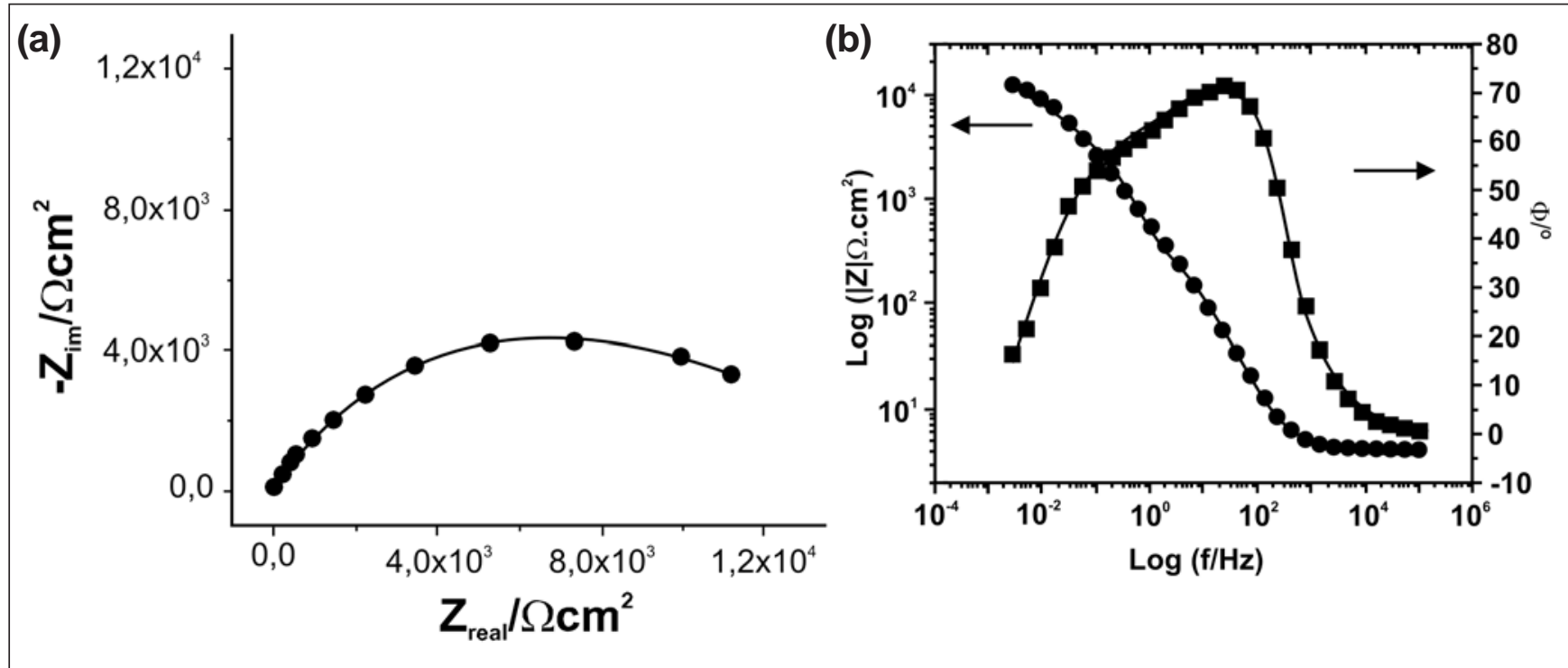

Figura 3 - Diagramas de impedância na forma de (a) Nyquist e (b) Bode correspondentes ao aço inoxidável P558 imerso em NaCl $0,11 \mathrm{~mol} \mathrm{~L}^{-1}$ durante $10 \mathrm{~min}$. - - Pontos experimentais. - Simulação. $\mathrm{E}=$ potencial de circuito aberto.

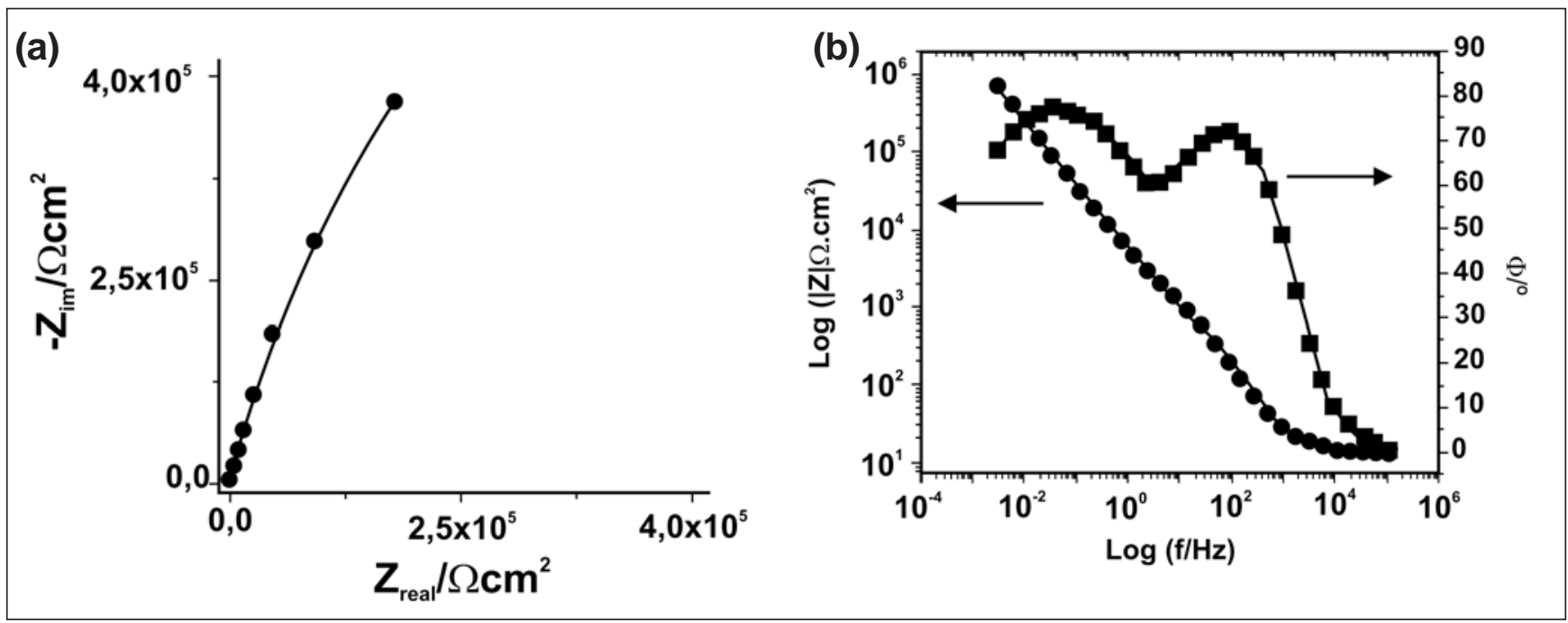

Figura 4 - Diagramas de impedância na forma de (a) Nyquist e (b) Bode correspondentes ao aço inoxidável P558 imerso em NaCl $0,11 \mathrm{~mol} \mathrm{~L}^{-1}$ durante $24 \mathrm{~h}$. @ Pontos experimentais. - Simulação. E = potencial de circuito aberto. 


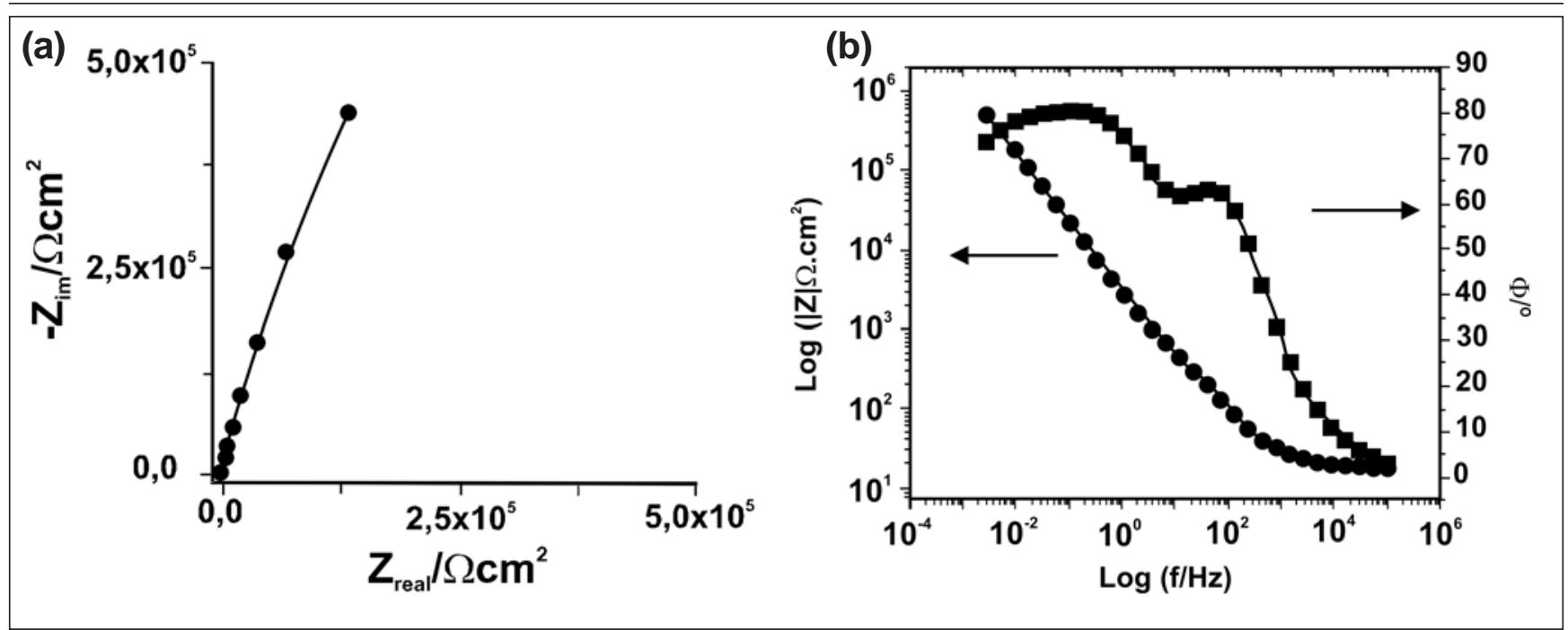

Figura 5 - Diagramas de impedância na forma de (a) Nyquist e (b) Bode correspondentes ao aço inoxidável P558 imerso em NaCl $0,11 \mathrm{~mol} \mathrm{~L}^{-1}$ durante $48 \mathrm{~h}$. - Pontos experimentais. - Simulação. $\mathrm{E}=$ potencial de circuito aberto.
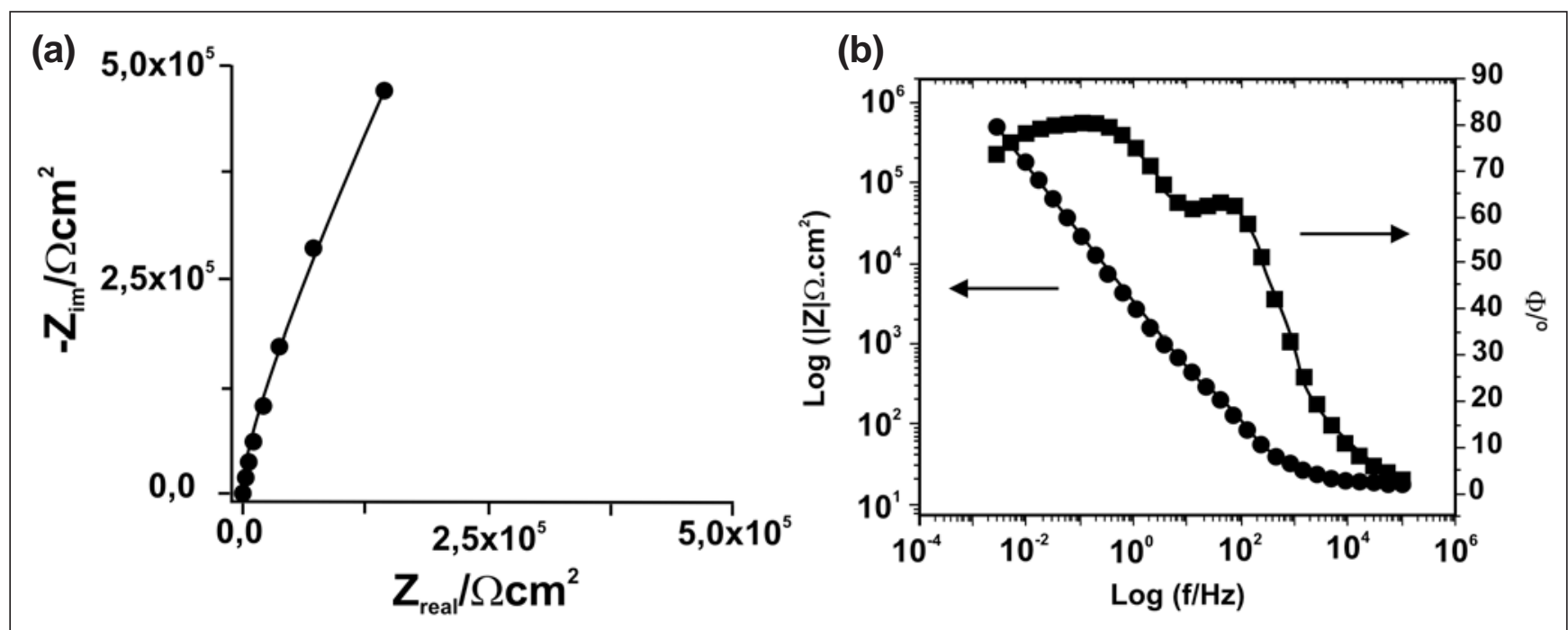

Figura 6 - Diagramas de impedância na forma de (a) Nyquist e (b) Bode correspondentes ao aço inoxidável P558 imerso em NaCl $0,11 \mathrm{~mol} \mathrm{~L}^{-1}$ durante $120 \mathrm{~h}$. @ Pontos experimentais. - Simulação. $\mathrm{E}=$ potencial de circuito aberto.

A interfase estudada aço P558/NaCl 0,11 $\mathrm{mol} \mathrm{L}^{-1}$ apresenta condição quase estacionária após 24h de imersão.

O emprego de circuitos equivalentes permitiu atribuir as mudanças com o tempo, nos resultados de EIE, à evolução de um segundo filme mais compacto, detectável no intervalo de freqüências mais baixas, inferiores a $10 \mathrm{~Hz}$.

\section{Referências bibliográficas}

[1] RONDELLI, G. et al. In vitro corrosion study by EIS of a nickelfree stainless steel for orthopaedic applications. Biomaterials, v.26, p.739-744, 2005.

[2] FINI M. et al. A new austenitic stainless steel with negligible nickel content: an in vitro and in vivo comparative investigation. Biomaterials, v. 24, p. 4929-4939, 2003.

[3] RECLARU L. et al. Comparative corrosion study of "Ni-free" austenitic stainless steels in view of medical applications. Acta Biomaterialia, v. 2, p. 433-444, 2006.

[4] GIORDANI E.J. et al. Effect of precipitates on the corrosionfatigue crack initiation of ISO 5832-9 stainless steel biomaterial. International Journal of fatigue, v. 26, p.1129-1136, 2004.

[5] CHENG X. et al. Electrochemically assisted co-precipitation of protein with calcium phosphate coatings on titanium alloy. Biomaterials, v. 25, p. 5395-5403, 2004.

[6] PADILHA, A.F. et al. Microstructures and mechanical properties of $\mathrm{Fe}-15 \% \mathrm{Cr}-15 \% \mathrm{Ni}$ austenitic stainless steels containing different levels of niobium additions submitted to various processing stages. Materials Processing Technology, v. 170, p. 89-96, 2005.

[7] VILLAMIL R.V.F. et al. Comparative electrochemical studies of 
Evolução temporal da interfase aço inoxidável P558/solução de cloreto de sódio por espectroscopia...

ISO 5832-9 and F 138 stainless steels in sodium chloride, $\mathrm{pH}=4.0$ medium. ASTM STP 1438 G. L. Winters and M. J. Nutt, Eds., Americam Society for Testing and Materials, West conshohocken, PA, 2003.

[8] VILLAMIL R.V.F. et al. Aços inoxidáveis aplicados em implantes ortopédicos: resistência à corrosão por pite do aço ISO 5832-9 em meio de soluções Ringer e Ringer Lactato. In: CONGRESSO BRASILEIRO DE ENGENHARIA E CIÊNCIA DOS MATERIAIS (CBECIMAT), 15. Natal: 2003.

[9] VILLAMIL R.V.F. et al. Estudo comparativo dos aços inoxidáveis ISO 5832-9 e F138 em meio de $\mathrm{NaCl}$ $0,11 \mathrm{~mol} \mathrm{~L}^{-1}$ por impedância eletroquímica. In: CONGRESSO BRASILEIRO DE CORROSÃO (ABRACO), 23. Florianópolis, SC: 09 a 12 de setembro de 2003.
[10] VILLAMIL R.V.F. et al. Emprego da impedância eletroquímica na caracterização de filmes passivos formados sobre o aço ISO 5832-9 em meio de $\mathrm{NaCl} 0,11$ mol $\mathrm{L}^{-1}$. In: CONGRESSO ANUAL DA ABM, 59. São Paulo, Brasil.

[11] VILLAMIL R.V.F. et al. Estudos por impedância eletroquímica a diferentes potenciais de um aço inoxidável isento de níquel em meios de cloreto de sódio. In: REUNIÃOANUALDASOCIEDADE BRASILEIRA DE QUÍMICA, 27 E CONGRESSO LATINOAMERICANO DE QUÍMICA, 26. São Paulo: 2004.

[12] AFONSO M.L. et al. Estudo comparativo do comportamento eletroquímico dos aços inoxidáveis UNS S3254 e ISO 5832-9 em $\mathrm{NaCl}$ 0,11 mol L-1. In SIBEE 2004.

[13] VILLAMIL R.V.F. et al. Estudo comparativo por MEV e EDS dos aços inoxidáveis austeníticos F138 e P558 aplicados em implantes ortopédicos. In: CONGRESSO LATINOAMERICANO DE ÓRGÃOS ARTIFICIAIS (COLAOB), 2006.

[14] VILLAMIL R.V.F. et al. Estudo do aço inoxidável P558, isento de níquel, por microscopia eletrônica de varredura. In: CONGRESSO LATINOAMERICANO DE CORROSÃO (LATINCORR), 2006. Trabalho aceito.

[15] VILLAMIL R.V.F. et al. Efeito DO pH e da temperatura no comportamento eletroquímico do aço P 558 em solução fisiológica. $\mathbf{A B M}, 2006$.

[16] VILLAMIL R.V.F. et al. Estudo por impedância eletroquímica do aço inoxidável austenítico, isento de níquel, em meio de cloreto de sódio e Ringer Lactanto. SIBAE, 2006.

Artigo recebido em 30/07/2006 e aprovado em 05/10/2006.
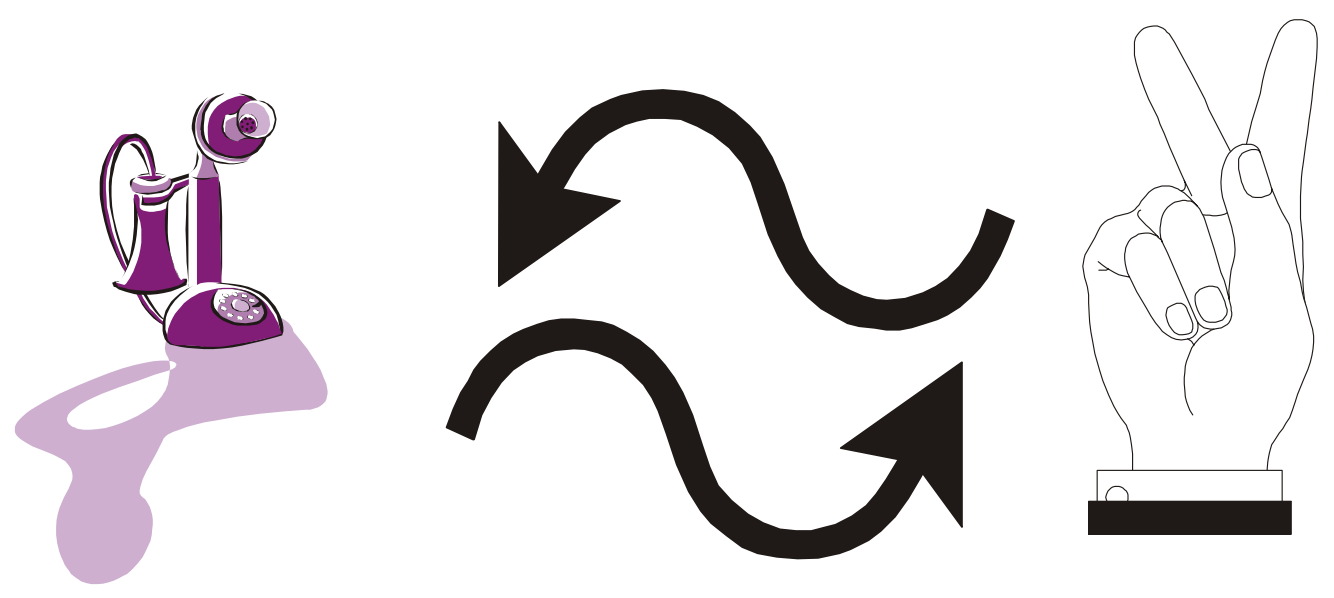

Se é assim que você se comunica com sua revista técnica...

Está na hora de você mudar.

\section{REM - Revista Escola de Minas}
a mais antiga revista técnica do setor mínero- metalúrgico da América do Sul

www.rem.com.br 